\title{
BRCA1 promoter hypermethylation, 53BP1 protein expression and PARP-1 activity as biomarkers of DNA repair deficit in breast cancer
}

William Jacot ${ }^{1,2^{*}}$, Simon Thezenas ${ }^{3}$, Romain Senal ${ }^{4}$, Cathy Viglianti ${ }^{4}$, Anne-Claire Laberenne ${ }^{4}$, Evelyne Lopez-Crapez ${ }^{2,4}$, Frédéric Bibeau ${ }^{2,5}$, Jean-Pierre Bleuse ${ }^{3}$, Gilles Romieu ${ }^{1}$ and Pierre-Jean Lamy ${ }^{2,4}$

\begin{abstract}
Background: Poly(adenosine diphosphate-ribose) polymerase 1 (PARP-1) and the balance between BRCA1 and 53BP1 play a key role in the DNA repair and cell stress response. PARP inhibitors show promising clinical activity in metastatic triple negative (TN) or BRCA-mutated breast cancer. However, a comprehensive analysis of PARP-1 activity, BRCA1 promoter methylation and 53BP1 expression in tumours without known BRCA1 mutation has not yet been carried out.

Methods: We investigated cytosolic PARP-1 activity, 53BP1 protein levels and BRCA1 promoter methylation in 155 surgical breast tumour samples from patients without familial breast cancer history or known BRCA1 mutations who were treated between January 2006 and November 2009 and evaluated their statistical association with classical predictive and prognostic factors.

Results: The mitotic count score was the only parameter clearly associated with PARP-1 activity. BRCA1 promoter hypermethylation (15.4\% of all cancers) was significantly associated with UPA and PAI-1 levels, tumour grade, mitotic count score, hormone receptor and HER2 negative status and TN profile (29\% of TN tumours showed BRCA1 promoter hypermethylation compared to $5 \%$ of grade II-III hormone receptor-positive/HER2-negative and 2\% of HER2-positive tumours). No statistical association was found between BRCA1 promoter hypermethylation and PARP-1 activity. High 53BP1 protein levels correlated with lymph node positivity, hormone receptor positivity, molecular grouping, unmethylated BRCA1 promoter and PARP-1 activity. In TN tumours, BRCA1 promoter methylation was only marginally associated with age, PARP-1 activity was not associated with any of the tested clinico-pathological factors and high 53BP1 protein levels were significantly associated with lymph node positivity. Only 3 of the 14 TN tumours with BRCA1 promoter hypermethylation presented high 53BP1 protein levels.

Conclusions: Breast cancers that harbour simultaneously high 53BP1 protein level and BRCA1 promoter hypermethylation and are the putative target population of drugs targeting DNA repair appear to be restricted to a small subgroup of TN tumours.
\end{abstract}

Keywords: Breast cancer, PARP-1, 53BP1, BRCA, Methylation

\footnotetext{
*Correspondence: William.Jacot@icm.unicancer.fr

'Department of Medical Oncology, Montpellier Cancer Institute, Montpellier,

France

${ }^{2}$ Translational Research Unit, Montpellier Cancer Institute, 208 rue des Apothicaires,

34298 Montpellier Cedex 5, France

Full list of author information is available at the end of the article
}

\section{Biomed Central}

(c) 2013 Jacot et al.; licensee BioMed Central Ltd. This is an open access article distributed under the terms of the Creative Commons Attribution License (http://creativecommons.org/licenses/by/2.0), which permits unrestricted use, distribution, and reproduction in any medium, provided the original work is properly cited. 


\section{Background}

Up-regulation of their DNA repair capacity represents a common mechanism used by cancer cells to survive DNA-damaging therapy [1]. Lack of efficient DNA repair by simultaneous loss or inhibition of two DNA repair pathways causes synthetic lethality and cell death, thus representing an attractive approach for cancer therapy [2]. For instance, BRCA-deficient cancer cells, in which DNA double strand break repair (DSB) by homologous recombination is deficient $[3,4]$, are particular sensitive to treatment with inhibitors of Poly(ADP-ribose) (PAR) polymerase 1 (PARP-1), a nuclear enzyme that recognizes and facilitates repair of DNA damage induced by oxidation, alkylation and ionizing radiation [2,5-7], showing reduced clonogenic survival and DNA DSB repair defects $[8,9]$. Moreover, the persistent single-strand breaks (SSB) formed upon PARP-1 inhibition cannot be repaired effectively in the absence of functional BRCA1 or BRCA2, resulting in accumulation of chromosomal abnormalities, cell cycle arrest and apoptosis [8,9]. Thus, PARP-1 may be an important target for BRCA-deficient breast cancer chemotherapy [8-11], as emphasized also by the clinical activity of the PARP inhibitor (PARP $i$ ) olaparib in patients with $B R C A$-mutated breast cancer [3]. Upregulation of PARP-1 expression and activity has been observed in a variety of human tumours [12,13]. In breast cancer, PARP-1 up-regulation has been associated with decreased survival [14] and triple-negative (TN) cancers (breast tumours in which estrogen receptor [ER], progesterone receptor [PR] and human epidermal growth factor receptor 2 [HER2] are not expressed) [15]. None of these studies considered PARP-1 activity together with BRCA1 functional status, except in the case of BRCA1-mutated cancers, which represent only around $5 \%$ of all breast cancers [16-18]. Loss of BRCA1 nuclear expression correlates with high tumour grade $(p<0.025)$ and ER-negative tumours. Absence or reduced BRCA1 expression in tumours without BRCA1 mutations appears linked to hypermethylation of the $B R C A 1$ promoter region [19], a condition reported in $9.1-37 \%$ of sporadic breast cancers and associated with infiltrating ductal type, high (grade II-III) tumour grade, ER negativity, basal markers expression, younger age at diagnosis, low BRCA1 mRNA expression and marked reduction or loss of BRCA1 protein expression [19-25]. Thus, BRCA1 promoter hypermethylation could be a marker of BRCA1 deficiency in the absence of BRCA1 mutation, as these two events appears mutually exclusive [24].

Some conditions, such as a loss of P53 binding protein 1 (53BP1, a protein involved in DNA damage checkpoint activation and DNA repair), could allow cells to tolerate BRCA1 deficiency. 53BP1 localizes to sites of DNA DSBs, promotes non-homologous end joining (NHEJ)-mediated repair and checkpoint activation and inhibits homologous recombination [26-29]. As BRCA1 promotes homologous recombination, it might counteract 53BP1 effect [30,31]. Thus, the balance between $53 \mathrm{BP} 1$ and BRCA1 regulates the competition between the NHEJ and homologous recombination pathways in DNA DSB repair [32]. In BRCA1 mutant/inactivated cells, repair by homologous recombination is defective and the error-prone NHEJ predominates, resulting in high sensitivity to DNA-damaging agents and PARPi. However, when both BRCA1 and 53BP1 are lost, repair by homologous recombination is restored and the sensitivity to DNA damaging agents is reduced, leading to resistance to cis-platinum and PARP $i$ in BRCA1-deficient cells, suggesting a critical role of $53 \mathrm{BP} 1$ in cancer cells in which $B R C A 1$ is mutated or epigenetically silenced [30-33]. Reduced 53BP1 expression has been reported in sporadic basal-like, TN and BRCA-mutated breast cancers [30]. It thus appears important to simultaneously evaluate 53BP1 status and BRCA1 mutation/promoter methylation to precisely estimate homologous recombination functionality in breast tumours.

Many PARP $i$ are presently in pre-clinical or clinical development, preferentially for patients with $B R C A$ deficient tumours or TN breast cancers, due to the overrepresentation of this breast cancer subtype in patients with $B R C A$ mutations. However, there is no validated screening test to identify the patients who may receive the most benefit from PARP $i$. Recent data show that most of the non-BRCA-mutated TN breast cancers do not benefit from such drugs, while some non-TN BRCA-mutated tumours could respond to PARP $i$ [34]. Moreover, two different groups $[35,36]$ recently reported that breast cancers with epigenetically silenced $B R C A 1$ are sensitive to PARP $i$ monotherapy, providing robust evidence to support the use of PARP $i$ in the treatment of selected sporadic $B R C A 1$-inactivated breast cancers. A comprehensive analysis of the PARP-1/BRCA1/53BP1 factors of DNA repair in the different breast cancer subtypes could enable this selection and promote the use of these compounds outside the TN subtype.

Here, we comprehensively and simultaneously evaluated the BRCA1/53BP1/PARP-1 repair network in three groups (HER2-positive, grade II-III hormone receptor [HR]-positive/HER2-negative and TN) of sporadic breast cancers $(\mathrm{n}=155)$ from patients without familial breast cancer history or known BRCA1 mutations to identify tumour population(s) with a theoretically high susceptibility to PARP $i$.

\section{Methods}

\section{Patients and tumour samples}

This is a retrospective monocentric study using samples from a research-dedicated tumour biobank (cytosol and DNA samples). A total of 556 consecutive patients with breast cancer referred to the Montpellier Cancer Institute 
between January 2006 and November 2009 were prospectively entered in the biobank database. The DNA collection was created using frozen, histologically proven and macro-dissected invasive breast cancer specimens that were primarily handled for $\mathrm{UPA} / \mathrm{PAI}-1$ testing [37]. Tumour samples dedicated to the molecular analysis were selected based on the immediate diagnosis by using frozen sections. Additional tumour tissue samples were then chosen after the definitive histological diagnosis (with quantification of the percentage of tumour cells) and grade assessment after fixation. This could be possible because frozen and formalin-fixed tumour tissue samples were selected from the same tumour areas. Only samples that contained at least $50 \%$ of tumour cells were used for uPA/PAI-1 testing. ER and PR protein expression was assessed by IHC using the anti-ER (clone 6 F11, 1:100, Leica Biosystems, United Kingdom) or anti-PR (clone PgR636, 1:400, Dako, Denmark) mouse monoclonal antibodies respectively. Tumours were considered as ERand PR-positive when more than $10 \%$ of tumour cells were stained by immunohistochemistry (IHC). HER2 protein expression was assessed by IHC using the A485 monoclonal antibody (Dako, Denmark). Breast cancers with HER2 scores of 0 and $1+$ were considered negative. Gene amplification was evaluated in HER2 2+ tumours using FISH or CISH. HER2 $3+$ tumours were considered as positive. Grade scoring, using the Scarf, Bloom and Richardson scoring method, modified as proposed by Elston and Ellis [38], was performed to score all tumours. For this study, 155 sporadic breast tumours from patients without familial breast cancer history or known $B R C A 1$ mutations were selected. Tumours were classified in three groups (grade II-III HR-positive/HER2-negative, $\mathrm{n}=57$; HER2-positive, $\mathrm{n}=50$; or $\mathrm{TN}, \mathrm{n}=48$ ) that were matched for age, $\mathrm{T}$ and $\mathrm{N}$ status. This study was reviewed and approved by the Montpellier Cancer Institute Review Board. All patients gave their written, informed consent. Although this was not a prognostic study, it followed the REMARK guidelines to enable future evaluation of the prognostic impact of the evaluated factors [39].

\section{Tissue processing and DNA extraction}

Each frozen tumour tissue sample was pulverized in liquid nitrogen with a grinder (Cryobroyeur-2000P Automatique, Rivoire, Montpellier, France) and then homogenized with a Polytron homogenizer (Glen Mills, Clifton, NJ) using a Triton buffer/tissue ratio of 10:1 (vol/wt; Triton buffer 1\%, $2 \mathrm{~mL} \mathrm{10 \%} \mathrm{Triton} \mathrm{X-100} \mathrm{in} 18 \mathrm{~mL}$ of Tris -buffered Saline [TBS, $50 \mathrm{mM}$ Tris, $150 \mathrm{mM} \mathrm{NaCl}$ ], pH 8.5) [37]. Homogenates were centrifuged at $10000 \times \mathrm{g}$ for 15 minutes. The supernatants were used to prepare cytosols and the total protein content was quantified using the Pierce assay (BCA Protein Assay Kit, Pierce Biotechnology, Rockford, IL) as previously described [37]. Total genomic DNA was extracted from the pellets using the QIAamp DNA Mini Kit (Qiagen $\mathrm{GmbH}$, Hilden, Germany) according to the manufacturer's protocol. DNA yield and purity were assessed using the Nanodrop (Thermo Fisher Scientific, Waltham, USA) by measuring the absorbance at $260 \mathrm{~nm}$ and $280 \mathrm{~nm}$. All samples had a 260/280 $\mathrm{nm}$ ratio higher than 1.7. DNA was stored at $-20^{\circ} \mathrm{C}$ in TE buffer $(10 \mathrm{mM}$ Tris and $0.5 \mathrm{mM}$ EDTA, $\mathrm{pH} 7.6$ ).

\section{PARP-1 activity}

The Trevigen HT Universal 96-well PARP Assay Kit (HT Universal Colorimetric PARP Assay Kit with Histonecoated Strip Wells, Trevigen, Gaithersburg, MD, USA) assesses cytosolic PARP-1 activity by measuring the incorporation of biotinylated poly(ADP-ribose) onto histone proteins in a 96-well strip format. $50 \mu \mathrm{l}$ of $1 \times$ PARP Buffer was added to rehydrate the histone-coated wells for 30 minutes and then removed. The PARP-HSA standard was used to obtain a standard curve with an activity range from $1 \mathrm{mU}$ to $1 \mathrm{U}$. Cytosol samples were diluted in PARP Buffer in order to contain at least $20 \mu \mathrm{g}$ of protein and $25 \mu \mathrm{L}$ were added in each well. Then, $25 \mu \mathrm{l}$ of $1 \times$ PARP Cocktail (obtained by diluting $25 \mu \mathrm{L}$ of $10 \times$ PARP Cocktail and $25 \mu \mathrm{L}$ of $10 \times$ Activated DNA in $1 \times$ PARP buffer) were added to each well and incubated at room temperature for 60 minutes. After two washes with $200 \mu \mathrm{L} 1 \times \mathrm{PBS}+0.1 \%$ Triton X-100 and two washes with $200 \mu \mathrm{L} 1 \times$ PBS, $50 \mu \mathrm{L}$ of $1 \times$ Strep-HRP was added and incubated at room temperature for 60 minutes. Wells were washed as before and $50 \mu \mathrm{L}$ of pre-warmed TACS-Sapphire substrate was added and incubated in the dark at room temperature for 15 minutes. Reactions were stopped with $50 \mu \mathrm{L} 0.2 \mathrm{M}$ $\mathrm{HCl}$. Absorbance was read at $450 \mathrm{~nm}$ and the concentration values of the diluted samples were calculated from the standard curves and expressed in U/mL. PARP-1 activity was normalized to the protein concentration and results were expressed in $\mathrm{U} / \mathrm{mg}$ of protein $(\mathrm{U} / \mathrm{mgP})$.

\section{BRAC1 promoter methylation status}

DNA methylation patterns at the CpG islands of the $B R C A 1$ promoter were assessed using a methylationspecific PCR assay [40]. This method distinguishes unmethylated and methylated alleles on the basis of sequence changes following bisulphite treatment of DNA that converts only unmethylated cytosines to uracil. Bisulphite treatment was performed using the EpiTect Bisulfite Kit (QIAGEN GmbH, Hilden, Germany). PCRs were performed on an Eppendorf Mastercycler ${ }^{\ominus}$ apparatus (Eppendorf, Hamburg, Germany) with the EpiTect MSP-PCR Kit (QIAGEN GmbH, Hilden, Germany) and specific primers designed for methylated or unmethylated BRCA1 DNA sequences [40]. EpiTect PCR Control DNA Set (Qiagen Hindel, Germany) containing both bisulfite converted methylated and unmethylated DNA and 
unconverted unmethylated DNA were also added as MS-PCR controls. Seven $\mu \mathrm{L}$ of each PCR product was loaded directly onto $1 \%$ agarose $+3 \%$ Nusieve GTG agarose gel, stained with $1 \mu \mathrm{L} / 10 \mathrm{ml} \mathrm{SYBR}{ }^{\circ}$ Safe DNA gel stain and visualized under UV light.

\section{BP1 protein quantification}

53BP1 concentration in the tumour cytosol samples was determined using the TP53BP1 ELISA kit (Cusabio, Wuhan, Hubei Province 430223, P.R.China). Protein concentration in cytosols ranged from 0.5 to $20 \mathrm{mg} / \mathrm{mL}$. For 53BP1 quantification $100 \mu \mathrm{L}$ of pure cytosol were used for each sample. $100 \mu \mathrm{l}$ of each sample and standards were incubated at $37^{\circ} \mathrm{C}$ for 2 hours to allow binding of 53BP1 to the immobilized anti-TP53BP1 antibody. After removal of unbound material without washing, each well was incubated at $37^{\circ} \mathrm{C}$ with $100 \mu \mathrm{L}$ of a biotin-conjugated antibody specific for TP53BP1 for one hour. After three washes, avidin-conjugated Horseradish Peroxidase (HRP) was added at $37^{\circ} \mathrm{C}$ for one hour. Following a wash to remove any unbound avidin-HRP, $90 \mu \mathrm{l}$ of TMB substrate solution was added for $30 \mathrm{~min} .50 \mu \mathrm{l}$ of Stop Solution was added into each well and absorbance was read at $450 \mathrm{~nm}$ with an MRX spectrophotometer (Dynatech laboratories). The range of standardization goes from $6.25 \mathrm{pg} / \mathrm{ml}$ to $400 \mathrm{pg} / \mathrm{ml}$ with a limit of detection of $2 \mathrm{pg} / \mathrm{ml}$. 53BP1 levels were standardized to the total protein content and results expressed in $\mathrm{pg} / \mathrm{mgP}$.

\section{Statistical methods}

In this monocentric retrospective study, our main goal was to evaluate the correlations of clinico-pathological features with PARP-1 activity, 53BP1 expression and $B R C A 1$ promoter hypermethylation. Categorical variables (all parameters precluding their concomitant use in adjuvant decision making) were reported by means of contingency tables. To investigate the association of classical clinico-pathological parameters with PARP-1 activity, 53BP1 protein level and BRCA1 gene promoter methylation, univariate analyses were performed for categorical variables using the Pearson's chi-square test or the Fisher's exact test when applicable. For continuous variables, medians and ranges were computed. The nonparametric Kruskal-Wallis test or the Mann Whitney test were used, as appropriate, to evaluate significant differences between groups of interest. Spearman's correlation was performed to investigate the strength of the relationship between pairs of variables. The Kaplan-Meier method was used to estimate the survival rates from the date of surgery until the date of the event of interest. Median survivals were presented with 95\% confidence interval $(95 \% \mathrm{CI})$. For OS, the event was death whatever the cause. Patients lost to follow-up were censored at the date of the last documented visit. For RFS, the event was recurrence. Patients alive at the last follow-up without recurrence were censored at the last follow-up date. Patients who died without recurrence were censored at the date of death. All $p$ values reported are two-sided and the significance level was set at 5\% $(\mathrm{p}<0.05)$. Statistical analysis was performed using the STATA 11 software (Stata Corporation, College Station, TX).

\section{Results}

\section{Patients' and tumours' characteristics}

A total of 155 patients with breast cancers that were classified in three molecular (HER2-positive, HR-positive / HER2-negative and TN) groups were selected for this study. The median age was 54 years (range 29-75 years). The main clinico-pathological characteristics of the population are summarized in Table 1. As only one tumour was classified as grade I and tubule formation score 1 and none as nuclear pleomorphism score 1 , tumours with grade I and II and tubule formation scores 1 and 2 were grouped for statistical analyses.

\section{PARP-1 activity}

The mean PARP-1 activity (U/mg of cytosolic protein) was 12.2 (standard deviation: 17.02), with a median of 7.0 (range: 1.0 to 114.2). No significant difference was observed in the three tumour groups concerning PARP-1 activity. Only the mitotic count score was clearly correlated with PARP-1 activity, using either the mean $(p=0.007)$, median (Figure 1 and Table 1) or the upper quartile limit $(p=0.03)$ as cut-off values. In addition, grade significantly $(p=0.02)$ correlated with PARP-1 activity using the mean as cut-off value. Using the mitotic count score as a continuous variable, a weak correlation was found between the number of mitoses and PARP-1 cytosolic activity (Spearman correlation coefficient: $0.234, p=0.003$ ).

\section{BRCA1 promoter methylation}

Bisulphite treatment was successfully performed for all samples. BRCA1 promoter hypermethylation was detected in 18 tumours (Additional file 1: Table S1) and was significantly associated with the TN status. Indeed, in $29 \%(14 / 48)$ of $\mathrm{TN}$ breast tumours BRCA1 promoter was hypermethylated compared to $5 \%$ (3/57) of HRpositive/HER2-negative and 2\% (1/50) of HER2-positive tumours (Table 1). BRCA1 promoter hypermethylation was significantly associated also with uPA and PAI-1 levels, grade and mitotic count score and ER-, PR- or HER2-negative status. No statistical association was found between $B R C A 1$ promoter hypermethylation and PARP-1 cytosolic activity.

\section{BP1 protein expression level}

53BP1 protein expression could not be determined in three tumours, due to insufficient amount of biological 
Table 1 Patients and tumours characteristics

\begin{tabular}{|c|c|c|c|c|c|c|c|c|c|}
\hline \multirow[b]{2}{*}{ Patients' characteristics } & \multirow[b]{2}{*}{ N (\%) } & \multicolumn{5}{|c|}{$\begin{array}{c}\text { PARP activity (Low }<7 \mathrm{U} / \mathrm{mg} \text { Protein, } \\
\text { High } \geq 7 \mathrm{U} / \mathrm{mg} \text { Protein) }\end{array}$} & \multicolumn{3}{|c|}{ BRCA1 methylation status } \\
\hline & & Low n (\%) & High n (\%) & $p$ & Mean \pm SD & $p$ & $\begin{array}{l}\text { Methylated } \\
\text { n (\%) }\end{array}$ & $\begin{array}{l}\text { Not Methylated } \\
\text { n (\%) }\end{array}$ & $p$ \\
\hline Age at diagnosis (years) & & & & 0.92 & & 0.83 & & & 0.17 \\
\hline Median (range) & $54(29-75)$ & & & & & & & & \\
\hline$\leq 54$ & $80(51.6 \%)$ & $38(52.1 \%)$ & $42(51.2 \%)$ & & $11.7(13)$ & & $12(66.7 \%)$ & $68(49.6 \%)$ & \\
\hline$>54$ & $75(48.4 \%)$ & 35 (47.9\%) & $40(48.8 \%)$ & & $12.7(20.5)$ & & $6(33.3 \%)$ & $69(50.4 \%)$ & \\
\hline Menopausal status & & & & 0.87 & & 0.54 & & & 0.62 \\
\hline Pre-menopausal & $69(44.5 \%)$ & $33(45.2 \%)$ & $36(43.9 \%)$ & & $12.5(13.8)$ & & $9(50.0 \%)$ & $60(43.8 \%)$ & \\
\hline Post-menopausal & $86(55.5 \%)$ & $40(54.8 \%)$ & $46(56.1 \%)$ & & $11.9(19.3)$ & & $9(50.0 \%)$ & $77(56.2 \%)$ & \\
\hline T classification & & & & 0.67 & & 0.60 & & & 0.76 \\
\hline $\mathrm{T} 1$ & $76(49 \%)$ & $36(49.3 \%)$ & $40(48.8 \%)$ & & $14(21.1)$ & & $9(50.0 \%)$ & $67(48.9 \%)$ & \\
\hline $\mathrm{T} 2$ & 75 (48.4\%) & $36(49.3 \%)$ & $39(47.6 \%)$ & & $10.4(12)$ & & $9(50.0 \%)$ & $66(48.2 \%)$ & \\
\hline T3-4 & $4(2.6 \%)$ & $1(1.4 \%)$ & $3(3.7 \%)$ & & $10(3.7)$ & & 0 & $4(2.9 \%)$ & \\
\hline $\mathrm{N}$ classification & & & & 0.75 & & 0.8 & & & 0.71 \\
\hline NO & $106(68.4 \%)$ & 49 (67.1\%) & $57(69.5 \%)$ & & $12.4(18.1)$ & & $13(72.2 \%)$ & $93(67.9 \%)$ & \\
\hline $\mathrm{N}+$ & 49 (31.6\%) & 24 (32.9\%) & $25(30.5 \%)$ & & $11.8(14.6)$ & & $5(27.8 \%)$ & $44(32.1 \%)$ & \\
\hline Histology & & & & 0.27 & & 0.3 & & & 0.53 \\
\hline Ductal & $120(77.4 \%)$ & $53(72.6 \%)$ & 67 (81.7\%) & & $13.1(18.3)$ & & 15 (83.3\%) & $105(76.6 \%)$ & \\
\hline Lobular & $9(5.8 \%)$ & $4(5.5 \%)$ & $5(6.1 \%)$ & & $7.8(8.3)$ & & 0 & $9(6.6 \%)$ & \\
\hline Other & $26(16.8 \%)$ & $16(21.9 \%)$ & $10(12.2 \%)$ & & $9.6(12.5)$ & & $3(16.7 \%)$ & $23(16.8 \%)$ & \\
\hline Grade & & & & 0.23 & & 0.02 & & & 0.03 \\
\hline$|/| \mid$ & $1(0.6 \%) / 51$ (32.9\%) & $28(38.4 \%)$ & $24(29.3 \%)$ & & $9.2(12.8)$ & & $2(11.1 \%)$ & $50(36.5 \%)$ & \\
\hline III & $103(66.5 \%)$ & $45(61.6 \%)$ & $58(70.7 \%)$ & & $13.7(18.7)$ & & 16 (88.9\%) & $87(63.5 \%)$ & \\
\hline Mitotic count score & & & & 0.04 & & 0.003 & & & 0.04 \\
\hline 1 & $31(20 \%)$ & $20(27.4 \%)$ & $11(13.4 \%)$ & & $8.3(13.6)$ & & $1(5.6 \%)$ & $30(21.9 \%)$ & \\
\hline 2 & $62(40 \%)$ & $30(41.1 \%)$ & 32 (39.0\%) & & $10.8(16.2)$ & & $5(27.8 \%)$ & $57(41.6 \%)$ & \\
\hline 3 & $62(40 \%)$ & $23(31.5 \%)$ & $39(47.6 \%)$ & & $15.6(18.8)$ & & $12(66.7 \%)$ & $50(36.5 \%)$ & \\
\hline ER & & & & 0.88 & & 0.66 & & & 0.001 \\
\hline Positive & $88(56.8 \%)$ & $41(56.2 \%)$ & $47(57.3 \%)$ & & $12.1(16.9)$ & & $4(22.2 \%)$ & $84(61.3 \%)$ & \\
\hline Negative & $67(43.2 \%)$ & $32(43.8 \%)$ & $35(42.7 \%)$ & & $12.4(17.3)$ & & $14(77.8 \%)$ & $53(38.7 \%)$ & \\
\hline PR & & & & 0.94 & & 0.75 & & & 0.01 \\
\hline Positive & $59(38.1 \%)$ & $28(38.4 \%)$ & $31(37.8 \%)$ & & $11.5(14.3)$ & & $2(11.1 \%)$ & $57(41.6 \%)$ & \\
\hline Negative & $96(61.9 \%)$ & $45(61.6 \%)$ & $51(62.2 \%)$ & & $12.6(18.6)$ & & $16(88.9 \%)$ & $80(58.4 \%)$ & \\
\hline HER2 & & & & 0.62 & & 0.5 & & & 0.01 \\
\hline Positive & $50(32.3 \%)$ & $25(34.2 \%)$ & $25(30.5 \%)$ & & $9.7(11.3)$ & & $1(5.6 \%)$ & 49 (35.8\%) & \\
\hline Negative & $105(67.7 \%)$ & $48(65.8 \%)$ & $57(69.5 \%)$ & & $13.4(19.1)$ & & 17 (94.4\%) & $88(64.2 \%)$ & \\
\hline Molecular profile grouping & & & & 0.81 & & 0.68 & & & $<0.001$ \\
\hline HER2+ & $50(32.3 \%)$ & $25(34.2 \%)$ & $25(30.5 \%)$ & & $9.7(11.3)$ & & $1(5.6 \%)$ & 49 (35.8\%) & \\
\hline $\mathrm{HR}+/ \mathrm{HER} 2-$ & $57(36.7 \%)$ & $25(34.2 \%)$ & $32(39.0 \%)$ & & $13.4(19.9)$ & & $3(16.7 \%)$ & $54(39.4 \%)$ & \\
\hline Triple negative & $48(31 \%)$ & $23(31.5 \%)$ & $25(30.5 \%)$ & & $13.4(18.3)$ & & $14(77.8 \%)$ & $34(24.8 \%)$ & \\
\hline uPA level ( $\geq 3$ ) & & & & 0.37 & & 0.3 & & & 0.01 \\
\hline High & $97(62.6 \%)$ & $43(58.9 \%)$ & $54(65.9 \%)$ & & $12.9(17)$ & & $16(88.9 \%)$ & 81 (59.1\%) & \\
\hline Low & $58(37.4 \%)$ & 30 (41.1\%) & $28(34.1 \%)$ & & $11(17.2)$ & & $2(11.1 \%)$ & $56(40.9 \%)$ & \\
\hline
\end{tabular}


Table 1 Patients and tumours characteristics (Continued)

\begin{tabular}{|c|c|c|c|c|c|c|c|c|c|}
\hline PAI-1 level ( $\geq 14$ ) & & & & 0.32 & & 0.42 & & & 0.03 \\
\hline High & 112 (72.3\%) & $50(68.5 \%)$ & $62(75.6 \%)$ & & $11.4(12.4)$ & & 17 (94.4\%) & $95(69.3 \%)$ & \\
\hline Low & $43(27.7 \%)$ & 23 (31.5\%) & $20(24.4 \%)$ & & $14.2(25.5)$ & & $1(5.6 \%)$ & 42 (30.7\%) & \\
\hline PARP Activity & & & & & & & & & 0.82 \\
\hline$\leq 2.6 \mathrm{U} / \mathrm{mg}$ Prot & $39(25.2 \%)$ & - & - & - & - & - & $4(22.2 \%)$ & 35 (25.5\%) & \\
\hline $2.7-7$ & 42 (27.1\%) & - & - & - & - & - & $6(33.3 \%)$ & $36(26.3 \%)$ & \\
\hline $7.1-14$ & 37 (23.9\%) & - & - & - & - & - & $3(16.7 \%)$ & $34(24.8 \%)$ & \\
\hline$>14$ & 37 (23.9\%) & - & - & - & - & - & $5(27.8 \%)$ & $32(23.4 \%)$ & \\
\hline
\end{tabular}

sample. The mean 53BP1 protein level in the remaining 152 tumours was $12.5 \mathrm{pg} / \mathrm{mgP}$ (median: $9.6 \mathrm{pg} / \mathrm{mgP}$; range: $2.0-93.0 \mathrm{pg} / \mathrm{mgP}$ ) (Table 2 ). High ( $\geq 9.6 \mathrm{pg} / \mathrm{mgP}$ ) 53BP1 levels correlated with molecular grouping (63.2\% of HR-positive/HER2-negative vs. $47.9 \%$ of HER2-positive and $36.2 \%$ of TN tumours, $p=0.022$ ), lymph node positivity (43.3\% of N0 vs. $64.6 \%$ of N1+ tumours, $p=0.015$ ), ER positivity (59.8\% of ER-positive $v s .36 .9 \%$ of ER-negative tumours, $p=0.005)$, PR positivity (62.7\% of PR-positive $v s$. $41.9 \%$ of PR-negative cancers, $p=0.013)$, unmethylated $B R C A 1$ promoter (53\% of unmethylated $v s .27 .8 \%$ of methylated cancers, $p=0.045)$ and PARP-1 activity (60.8\% of tumours with high ( $\geq 7 \mathrm{U} / \mathrm{mg}$ Prot) PARP-1 activity vs. $38.4 \%$ of tumours with low $(<7 \mathrm{U} / \mathrm{mg}$ Prot $)$ PARP-1 activity, $p=0.006$ using PARP-1 median value as a cut-off; $p=0.048$ categorizing PARP-1 values as quartiles [Table 2]). No correlation was found between PARP-1 activity and 53BP1 levels using continuous variables (Additional file 2: Figure S1). Both high 53BP1 levels and $B R C A 1$ promoter hypermethylation were observed in three TN tumours and two non-TN tumours (Additional file 1: Table S1).

\section{The BRCA1 / 53BP1/ PARP-1 pathway in triple negative breast cancers}

BRCA1 promoter methylation status, 53BP1 protein levels and PARP-1 activity in the $48 \mathrm{TN}$ breast cancers and their clinico-pathologically data are presented in Additional file 3: Table S2. In this group, only age was almost negatively associated with BRCA1 promoter methylation (83.3\% of cancers were unmethylated in patients $>54$ vs. $58.3 \%$ in patients $\leq 54$ years, $p=0.057$ ). PARP-1 activity was not associated with any of the tested clinico-pathological features. High 53BP1 levels were significantly associated with lymph node positivity (24.2\% of N0 vs. $64.3 \%$ of N1+ cancer, $p=0.009$ ). The association of high 53BP1 and PAI-1 protein levels was almost significant $(43.2 \%$ of cancers with high vs. $10 \%$ of cancer with low PAI-1 protein levels, $p=0.052$ ). Only three of the 14 tumours with BRCA1 promoter

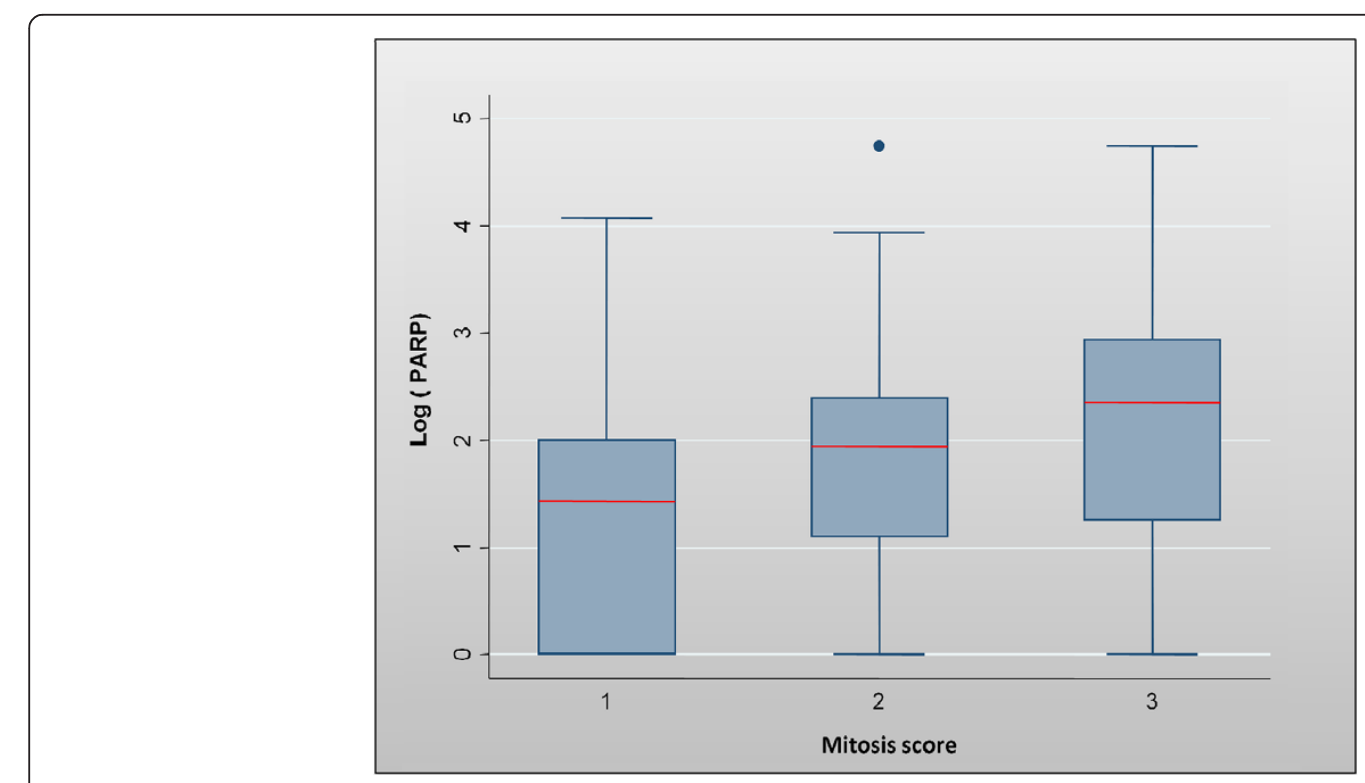

Figure 1 Correlation between PARP cytosolic level (logarithmic scale) and the mitotic count score. 
Table 2 53BP1 protein expression level and correlation with clinico-pathological parameters

\begin{tabular}{|c|c|c|c|c|}
\hline \multirow[b]{2}{*}{ Patients' characteristics } & \multirow[b]{2}{*}{$\mathrm{N}(\%)$} & \multicolumn{3}{|c|}{ 53BP1 protein expression level (Low $<9.6 \mathrm{U} / \mathrm{mg}$ Protein, High $\geq 9.6 \mathrm{pg} / \mathrm{mg}$ Protein) } \\
\hline & & Low n (\%) & High n (\%) & $p$ \\
\hline Age at diagnosis (years) & & & & 1 \\
\hline Median (range) & $54(29-75)$ & & & \\
\hline$\leq 54$ & $80(52.6 \%)$ & $40(52.6 \%)$ & $40(52.6 \%)$ & \\
\hline$>54$ & $72(47.4 \%)$ & $36(47.4 \%)$ & $36(47.5 \%)$ & \\
\hline Menopausal status & & & & 0.87 \\
\hline Pre-menopausal & $69(44.7 \%)$ & $34(44.7 \%)$ & $35(46.1 \%)$ & \\
\hline Post-menopausal & $83(55.3 \%)$ & $42(55.3 \%)$ & $41(53.9 \%)$ & \\
\hline T classification & & & & 0.57 \\
\hline $\mathrm{T} 1$ & 75 (49.3\%) & 37 (48.7\%) & $38(50 \%)$ & \\
\hline $\mathrm{T} 2$ & $73(48 \%)$ & $38(50 \%)$ & $35(46.1 \%)$ & \\
\hline T3-4 & $4(2.6 \%)$ & $1(1.3 \%)$ & $3(3.9 \%)$ & \\
\hline $\mathrm{N}$ classification & & & & 0.015 \\
\hline No & $104(68.4 \%)$ & $59(77.6 \%)$ & $45(59.2 \%)$ & \\
\hline $\mathrm{N}+$ & $48(31.6 \%)$ & $17(22.4 \%)$ & $31(40.8 \%)$ & \\
\hline Histology & & & & 0.44 \\
\hline Ductal & 117 (77\%) & $58(76.4 \%)$ & $59(77.6 \%)$ & \\
\hline Lobular & $9(5.9 \%)$ & $3(3.9 \%)$ & $6(7.9 \%)$ & \\
\hline Other & $26(17.1 \%)$ & 15 (19.7\%) & $11(14.5 \%)$ & \\
\hline Grade & & & & 0.46 \\
\hline I/ || & $1(0.7 \%) / 50(32.9 \%)$ & $23(30.3 \%)$ & $28(36.8 \%)$ & \\
\hline III & $101(66.4 \%)$ & $53(69.7 \%)$ & $48(63.2 \%)$ & \\
\hline ER & & & & 0.005 \\
\hline Positive & $87(57.2 \%)$ & $35(46.1 \%)$ & $52(68.4 \%)$ & \\
\hline Negative & $65(42.8 \%)$ & $41(53.9 \%)$ & $24(31.6 \%)$ & \\
\hline PR & & & & 0.013 \\
\hline Positive & $59(38.8 \%)$ & $22(28.9 \%)$ & $37(48.7 \%)$ & \\
\hline Negative & $93(61.2 \%)$ & $54(71.1 \%)$ & $39(51.3 \%)$ & \\
\hline HER2 & & & & 0.73 \\
\hline Positive & $48(31.6 \%)$ & $25(32.9 \%)$ & $23(30.3 \%)$ & \\
\hline Negative & $104(68.4 \%)$ & $51(67.1 \%)$ & $53(69.7 \%)$ & \\
\hline Molecular profile grouping & & & & 0.022 \\
\hline HER2+ & $48(31.6 \%)$ & $25(32.9 \%)$ & $23(30.3 \%)$ & \\
\hline $\mathrm{HR}+/ \mathrm{HER} 2-$ & $57(37.5 \%)$ & $21(27.6 \%)$ & $36(47.4 \%)$ & \\
\hline Triple Negative & 47 (30.9\%) & $30(39.5 \%)$ & $17(22.4 \%)$ & \\
\hline BRCA1 methylation Status & & & & 0.045 \\
\hline Methylated & $18(11.8 \%)$ & $13(17.1 \%)$ & $5(6.6 \%)$ & \\
\hline Not Methylated & $134(88.2 \%)$ & $63(82.9 \%)$ & $71(93.4 \%)$ & \\
\hline PARP activity & & & & 0.048 \\
\hline$\leq 2.6 \mathrm{U} / \mathrm{mg}$ Prot & 39 (25.6\%) & $21(27.6 \%)$ & $18(23.8 \%)$ & \\
\hline $2.7-7$ & $41(27 \%)$ & $27(35.5 \%)$ & $14(18.4 \%)$ & \\
\hline $7.1-14$ & $36(23.7 \%)$ & $14(18.4 \%)$ & $22(28.9 \%)$ & \\
\hline$>14$ & $36(23.7 \%)$ & $14(18.4 \%)$ & $22(28.9 \%)$ & \\
\hline
\end{tabular}


hypermethylation had high 53BP1 protein levels. No clinico-pathological criterion could specifically identify this breast cancer population.

As recommendations regarding ER and PR cut-offs are not clearly established worldwide, we used an alternative, North American, 1\% cut-off to define ER and PR positivity / negativity. Using this $1 \%$ threshold, the results were not significantly modified even if $2 \mathrm{TN}$ cases were reclassified as HR+/HER2- cases using this alternative cut-off ( 2 cases with a $1-9 \%$ ER status, none for PR status).

\section{Survival analyses}

Survival data were updated on June 10, 2012. At this time, after a median follow-up of 43.6 months (range 1.9 75.7 months), only 2 cancer-related deaths and 2 relapses were recorded (2 TN patients). The median 3-year OS and RFS were 0.986 (95\% CI 0.954 - 0.999) and 0.986 (95\% CI 0.954 - 0.999), respectively. This low number of relapses and deaths could be explained by a relatively brief followup, altogether with the fact that most of the tumours were small (pT1) and/or node negative tumours. In addition, considering the $\mathrm{TN}$ population, nearly all of the patients of this study received adjuvant chemotherapy. Even if the 2 events occurred in the TN population, the low number of events precludes a statistically robust analysis.

\section{Discussion}

This study reports a comprehensive analysis of the BRCA/ 53BP1/PARP-1 factors of DNA repair in the largest cohort of patients with sporadic breast cancer to date. Clinical studies are currently under way to evaluate the efficacy of PARP $i$ in patients with TN breast cancer. However, triple negativity alone does not appear to be a good surrogate marker for PARP $i$ clinical sensitivity [34] as important biological differences exist within this group of tumours. Moreover, it is important to know whether sub-population of HR-positive and HER2-positive patients might also be eligible for such therapy.

We found that PARP-1 activity correlated only with the mitotic count score, without statistical association with BRCA1 promoter hypermethylation. Using IHC, von Minckwitz et al. retrospectively evaluated the predictive and prognostic value of cytoplasmic (cPARP) and nuclear PARP (nPARP) expression in 638 pre-treatment biopsies from neoadjuvant anthracycline/taxane-treated patients [13]. High cPARP expression was significantly correlated with non-lobular histology, undifferentiated grade, positive nodal and negative HR status, but not with the HER2 status. Expression of cPARP was high in $35.5 \%$ of TN tumours, $24.6 \%$ of HER2-positive tumours and $18.0 \%$ of HR-positive/HER2-negative tumours. High cPARP expression was predictive of the achievement of pathologic complete response, particularly in HR-positive and HER2-negative tumours, and was a negative, but not independent prognostic factor of disease-free and overall survival. No correlation was found for nPARP expression. Ozretic et al. [41] investigated PARP expression in breast cancers with BRCA1 $(\mathrm{n}=66)$ or BRCA2 $(\mathrm{n}=27)$ mutations and in 53 sporadic breast cancers. Although they used the same PARP antibody described by von Minckwitz et al. [13], they did not observe significant cPARP staining. Conversely, nPARP expression was significantly increased in cancers with BRCA1 or BRCA2 mutations compared to sporadic tumours. No significant increase in nPARP expression was observed in the few sporadic TN breast cancers of their cohort. Their results suggest that nPARP and not cPARP expression is associated with BRCA-dependent DNA repair deficiency. However, their results cannot be extrapolated to the whole population of sporadic TN breast tumours due to the limited sample size. The results of the study by Rojo et al. [14] are consistent with the findings by Ozteric et al. They quantitatively evaluated nPARP-1 expression using a specific IHC signal intensity scanning assay in a range of normal to malignant breast lesions, including 330 patients treated for early breast cancer. nPARP-1 was overexpressed in about a third of ductal carcinoma in situ and infiltrating breast cancers and was associated with higher tumour grade, ERnegative tumours and TN phenotype. In this study, Ki-67 staining was used instead of mitotic count. As discrepancies are common between these two methods of proliferation evaluation, [42] a parallel cannot be drawn between this study and our results on this variable. Finally, multivariate analysis (median follow-up time: 4.8 years) indicated that nPARP-1 overexpression was an independent prognostic factor for both disease-free (HR 10.05; 95\% CI 5.42-10.66) and overall survival (HR 1.82; 95\% CI 1.322.52) [14]. These discordant results regarding the association of PARP quantification by IHC with prognosis could be linked to the fact that the IHC assay used for PARP determination detects both active and catalytically inactive, auto-modified PARP and not only functionally active PARP like in our study. However, to date, the question of the better way to evaluate tumoral PARP-1 activity (functional cytosolic assay as in our study, or morphological test such as IHC) is still open $[13,14,41]$.

In our series, $B R C A 1$ promoter hypermethylation was found in 18 tumours and was significantly associated with a more aggressive clinico-biological profile and with triple negativity. Indeed, in $29 \%$ of TN tumours $B R C A 1$ promoter was hypermethylated compared to $5 \%$ of HR-positive/HER2-negative and 2\% of HER2positive tumours, consistent with the $36.7 \%$ reported by Veek et al. in 68 non-inherited TN breast cancers [36]. Altogether, these results suggest that the analysis of $B R C A 1$ hypermethylation could be included in the current and prospective PARP $i$ clinical trials as a potential predictive biomarker. Wei et al. found a strong correlation 
between $E R$ promoter and $B R C A 1$ promoter methylation, suggesting a higher frequency of $B R C A 1$ methylation in HR-negative breast cancers (no information was available on the HER2 status of these tumours) [43]. In the study evaluating the clinical impact of $B R C A 1$ promoter methylation in 135 Bulgarian HR-positive and HR-negative patients, Krasteva et al. reported that hypermethylation was present in $17.04 \%$ of the cases. Surprisingly, patients with $B R C A 1$ promoter hypermethylation displayed favourable clinical status as their tumours were smaller in size, lacked p53 gene mutations and were of lobular type [44]. BRCA1 promoter methylation was not significantly associated with ER, PR and HER2 status; however an evaluation of its association with the TN status was not reported. The presence of $B R C A 1$ promoter hypermethylation was not significantly associated with better overall survival $(\mathrm{HR}=0.47, p=0.2)$. No clear explanation of these discrepancies compared to other publications was proposed by the authors. No conclusion could be issued in our present study regarding the impact of these biomarkers status on survival, considering the relatively brief median follow-up of our population. However, this information will be studied later, after a significantly longer follow-up, allowing the occurrence of more events. Finally, we show that 53BP1 protein expression levels was significantly correlated with molecular grouping $(63.2 \%$ of HR-positive/HER2-negative $v s .47 .9 \%$ of HER2-positive and $36.2 \%$ of TN tumours) and unmethylated BRCA1 promoter (53\% of unmethylated $v s$. $27.8 \%$ of methylated cancers). Regarding definition of ER and PR positivity, recommendations regarding ER and PR cut-offs are not clearly established worldwide. We used in this study an European 10\% cut-off to consider positive or negative ER and PR status [45]. This 10\% cut-off can be considered as a standard of care in many countries. The $1 \%$ cut-off can be considered as another, North American, standard. However, our results were not significantly modified by the use of this $1 \%$ threshold for ER ( 2 TN cases) and PR positivity (no TN cases), and thus cannot be explained by the use of one or another ER/PR positivity threshold.

\section{Conclusions}

In our study, the association of $B R C A 1$ promoter methylation and high 53BP1 protein levels was a rare event, even in the TN group. As this association appears to be the best situation to predict PARP $i$ clinical activity (because loss of 53BP1 leads to partial restoration of homologous recombination and resistance to PARP i) [33] these results pledge for a strict selection of the target population of future trials involving these agents, and could, at the same time, explain the negative results of previous trials that did not include such strict selection [46]. A retrospective analysis of BRCA1 promoter methylation and 53BP1 protein levels in the patients enrolled in such trials could help confirm the predictive impact of this tumour profile. In addition, evaluation of the 53BP1 protein levels in cases harbouring deleterious mutations in other less common homologous recombination genes with moderate penetrance, such as PALB2 [47,48], need to be performed, as well as determination of the PALB2 methylation status of this gene in PALB2 non-mutated cases, as PALB2-deficient cells appears to be sensitive to PARPi [49].

\section{Additional files}

Additional file 1: Table S1. Patients and Tumours Characteristics of the 18 breast cancers with BRCA1 promoter methylation.

Additional file 2: Figure S1. Correlation between PARP-1 activity and 53BP1 levels.

Additional file 3: Table S2. Patients and Tumours Characteristics of the 48 triple negative breast cancers.

\section{Abbreviations}

53BP1: P53 binding protein 1; BRCA1: Breast cancer type 1 susceptibility protein; CISH: Chromogenic in situ hybridization; DNA: DeoxyriboNucleic acid; DSB: Double strand break; EDTA: EthyleneDiamineTetraacetic acid; ER: Estrogen receptor; FISH: Fluorescent in situ hybridization; Grade: Scarf, bloom and Richardson scoring method, modified as proposed by Elston and Ellis; HER2: Human epidermal growth factor receptor 2; HR: Hormone receptors; IHC: ImmunoHistoChemistry; NHEJ: Non-homologous end joining; PAI-1: Plasminogen activator inhibitor type 1; PARP-1: Poly(ADP-Ribose) polymerase 1; PARPi: PARP inhibitor; PCR: Polymerase chain reaction; PR: Progesterone receptor; SSB: Single-strand breaks; TN: Triple negative breast cancers; uPA: urokinase-type plasminogen activator.

\section{Competing interests}

The authors declare that they have no competing interests.

\section{Authors' contributions}

WJ participated in the conception and design of the study, provided study patients and material, collected, assembled and interpreted the data and drafted the manuscript. ST participated in the conception and design of the study, participated in the design of the study and performed the statistical analysis. RS collected and assembled the data and carried out the assays. CV collected and assembled the data and participated in the assays. ACL collected and assembled the data and carried out the assays. ELC collected and assembled the data and carried out the assays. FB provided study patients and material, collected and assembled the data. JPB participated in the conception and design of the study and helped to draft the manuscript. GR participated in the conception and design of the study, provided study patients and material and helped to draft the manuscript. PJL participated in the conception and design of the study, provided study material, participated in the assays, collected, assembled and interpreted the data and helped to draft the manuscript. All authors read and approved the final manuscript.

\section{Acknowledgments}

The authors want to thank Martine Pascal and Isabelle Pantel for their technical assistance.

This study was supported by a research grant from Sanofi-Aventis France. Part of this study was presented at the 2012 and 2013 AACR Annual Meetings.

\section{Author details}

'Department of Medical Oncology, Montpellier Cancer Institute, Montpellier, France. ${ }^{2}$ Translational Research Unit, Montpellier Cancer Institute, 208 rue des Apothicaires, 34298 Montpellier Cedex 5, France. ${ }^{3}$ Department of Biostatistics, Montpellier Cancer Institute, Montpellier, France. ${ }^{4}$ Department of Biology and Oncogenetic, Montpellier Cancer Institute, Montpellier, France. ${ }^{5}$ Department of Pathology, Montpellier Cancer Institute, Montpellier, France. 
Received: 28 June 2013 Accepted: 23 October 2013

Published: 5 November 2013

\section{References}

1. Liu X, Palma J, Kinders R, Shi Y, Donawho C, Ellis PA, Rodriguez LE, ColonLopez M, Saltarelli M, LeBlond D, et al: An enzyme-linked immunosorbent poly(ADP-ribose) polymerase biomarker assay for clinical trials of PARP inhibitors. Anal Biochem 2008, 381(2):240-247.

2. Helleday T, Petermann E, Lundin C, Hodgson B, Sharma RA: DNA repair pathways as targets for cancer therapy. Nat Rev Cancer 2008, 8(3):193-204.

3. Tutt A, Robson M, Garber JE, Domchek SM, Audeh MW, Weitzel JN, Friedlander M, Arun B, Loman N, Schmutzler RK, et al: Oral poly(ADPribose) polymerase inhibitor olaparib in patients with BRCA1 or BRCA2 mutations and advanced breast cancer: a proof-of-concept trial. Lancet 2010, 376(9737):235-244.

4. Wooster R, Weber BL: Breast and ovarian cancer. N Engl J Med 2003, 348(23):2339-2347.

5. D'Amours D, Desnoyers S, D'Silva I, Poirier GG: Poly(ADP-ribosyl)ation reactions in the regulation of nuclear functions. Biochem J 1999, 342(Pt 2):249-268.

6. Schreiber V, Dantzer F, Ame JC, de Murcia G: Poly(ADP-ribose): novel functions for an old molecule. Nat Rev Mol Cell Biol 2006, 7(7):517-528.

7. Ame JC, Spenlehauer C, de Murcia G: The PARP superfamily. Bioessays 2004, 26(8):882-893.

8. Bryant HE, Schultz N, Thomas HD, Parker KM, Flower D, Lopez E, Kyle S, Meuth M, Curtin NJ, Helleday T: Specific killing of BRCA2-deficient tumours with inhibitors of poly(ADP-ribose) polymerase. Nature 2005, 434(7035):913-917.

9. Farmer H, McCabe N, Lord CJ, Tutt AN, Johnson DA, Richardson TB, Santarosa M, Dillon KJ, Hickson I, Knights C, et al: Targeting the DNA repair defect in BRCA mutant cells as a therapeutic strategy. Nature 2005, 434(7035):917-921.

10. Curtin NJ: PARP inhibitors for cancer therapy. Expert Rev Mol Med 2005, 7(4):1-20.

11. Curtin N: Therapeutic potential of drugs to modulate DNA repair in cancer. Expert Opin Ther Targets 2007, 11(6):783-799.

12. Domagala P, Huzarski T, Lubinski J, Gugala K, Domagala W: PARP-1 expression in breast cancer including BRCA1-associated, triple negative and basal-like tumors: possible implications for PARP-1 inhibitor therapy. Breast Cancer Res Treat 2011, 127(3):861-869.

13. von Minckwitz G, Muller BM, Loibl S, Budczies J, Hanusch C, Darb-Esfahani S, Hilfrich J, Weiss E, Huober J, Blohmer JU, et al: Cytoplasmic poly(adenosine diphosphate-ribose) polymerase expression is predictive and prognostic in patients with breast cancer treated with neoadjuvant chemotherapy. $J$ Clin Oncol 2011, 29(16):2150-2157.

14. Rojo F, Garcia-Parra J, Zazo S, Tusquets I, Ferrer-Lozano J, Menendez S, Eroles P, Chamizo C, Servitja S, Ramirez-Merino N, et al: Nuclear PARP-1 protein overexpression is associated with poor overall survival in early breast cancer. Ann Oncol 2012, 23(5):1156-1164.

15. Tuma RS: PARP inhibitors: will the new class of drugs match the hype? J Natl Cancer Inst 2009, 101(18):1230-1232.

16. Blackwood MA, Weber BL: BRCA1 and BRCA2: from molecular genetics to clinical medicine. J Clin Oncol 1998, 16(5):1969-1977.

17. Miki $Y$, Katagiri T, Kasumi F, Yoshimoto T, Nakamura Y: Mutation analysis in the BRCA2 gene in primary breast cancers. Nat Genet 1996, 13(2):245-247.

18. Miki Y, Swensen J, Shattuck-Eidens D, Futreal PA, Harshman K, Tavtigian S, Liu Q, Cochran C, Bennett LM, Ding W, et al: A strong candidate for the breast and ovarian cancer susceptibility gene BRCA1. Science 1994, 266(5182):66-71.

19. Bal A, Verma S, Joshi K, Singla A, Thakur R, Arora S, Singh G: BRCA1methylated sporadic breast cancers are BRCA-like in showing a basal phenotype and absence of ER expression. Virchows Arch 2012, 461(3):305-312.

20. Birgisdottir $V$, Stefansson OA, Bodvarsdottir SK, Hilmarsdottir H, Jonasson JG, Eyfjord JE: Epigenetic silencing and deletion of the BRCA1 gene in sporadic breast cancer. Breast Cancer Res 2006, 8(4):R38.

21. Lips EH, Mulder L, Hannemann J, Laddach N, Vrancken Peeters MT, van de Vijver MJ, Wesseling J, Nederlof PM, Rodenhuis S: Indicators of homologous recombination deficiency in breast cancer and association with response to neoadjuvant chemotherapy. Ann Oncol 2011, 22(4):870-876
22. Mirza S, Sharma G, Prasad CP, Parshad R, Srivastava A, Gupta SD, Ralhan R: Promoter hypermethylation of TMS1, BRCA1, ERalpha and PRB in serum and tumor DNA of invasive ductal breast carcinoma patients. Life SCi 2007, 81(4):280-287.

23. Wei M, Grushko TA, Dignam J, Hagos F, Nanda R, Sveen L, Xu J, Fackenthal J, Tretiakova M, Das S, et al: BRCA1 promoter methylation in sporadic breast cancer is associated with reduced BRCA1 copy number and chromosome 17 aneusomy. Cancer Res 2005, 65(23):10692-10699.

24. Lips EH, Mulder L, Oonk A, van der Kolk LE, Hogervorst FB, Imholz AL, Wesseling J, Rodenhuis S, Nederlof PM: Triple-negative breast cancer: BRCAness and concordance of clinical features with BRCA1-mutation carriers. Br J Cancer 2013, 108(10):2172-2177.

25. Birkbak NJ, Wang ZC, Kim JY, Eklund AC, Li Q, Tian R, Bowman-Colin C, Li Y, Greene-Colozzi A, Iglehart JD, et al: Telomeric allelic imbalance indicates defective DNA repair and sensitivity to DNA-damaging agents. Cancer Discov 2012, 2(4):366-375.

26. Wang B, Matsuoka S, Carpenter PB, Elledge SJ: 53BP1, a mediator of the DNA damage checkpoint. Science 2002, 298(5597):1435-1438.

27. Ward I, Kim JE, Minn K, Chini CC, Mer G, Chen J: The tandem BRCT domain of 53BP1 is not required for its repair function. J Biol Chem 2006, 281(50):38472-38477.

28. FitzGerald JE, Grenon M, Lowndes NF: 53BP1: function and mechanisms of focal recruitment. Biochem Soc Trans 2009, 37(Pt 4):897-904.

29. Huo Q, Yang Q: P53-binding protein 1: a new player for tumorigenesis and a new target for breast cancer treatment. Med Hypotheses 2011, 77(3):359-363

30. Bouwman P, Aly A, Escandell JM, Pieterse M, Bartkova J, van der Gulden H, Hiddingh S, Thanasoula M, Kulkarni A, Yang Q, et al: 53BP1 loss rescues BRCA1 deficiency and is associated with triple-negative and BRCAmutated breast cancers. Nat Struct Mol Biol 2010, 17(6):688-695.

31. Bunting SF, Callen E, Wong N, Chen HT, Polato F, Gunn A, Bothmer A, Feldhahn N, Fernandez-Capetillo O, Cao L, et al: 53BP1 inhibits homologous recombination in Brca1-deficient cells by blocking resection of DNA breaks. Cell 2010, 141(2):243-254.

32. Aly A, Ganesan S: BRCA1, PARP, and 53BP1: conditional synthetic lethality and synthetic viability. J Mol Cell Biol 2011, 3(1):66-74.

33. Jaspers JE, Kersbergen A, Boon U, Sol W, van Deemter L, Zander SA, Drost R, Wientjens $\mathrm{E}$, Ji J, Aly A, et al: Loss of 53BP1 causes PARP inhibitor resistance in Brca1-mutated mouse mammary tumors. Cancer Discov 2013, 3(1):68-81.

34. Gelmon KA, Tischkowitz M, Mackay H, Swenerton K, Robidoux A, Tonkin K, Hirte H, Huntsman D, Clemons M, Gilks B, et al: Olaparib in patients with recurrent high-grade serous or poorly differentiated ovarian carcinoma or triple-negative breast cancer: a phase 2, multicentre, open-label, non-randomised study. Lancet Oncol 2011, 12(9):852-861.

35. Drew Y, Mulligan EA, Vong WT, Thomas HD, Kahn S, Kyle S, Mukhopadhyay A, Los G, Hostomsky Z, Plummer ER, et al: Therapeutic potential of poly (ADP-ribose) polymerase inhibitor AG014699 in human cancers with mutated or methylated BRCA1 or BRCA2. J Natl Cancer Inst 2011, 103(4):334-346.

36. Veeck J, Ropero S, Setien F, Gonzalez-Suarez E, Osorio A, Benitez J, Herman JG, Esteller M: BRCA1 CpG island hypermethylation predicts sensitivity to poly(adenosine diphosphate)-ribose polymerase inhibitors. J Clin Oncol 2010, 28(29):e563-564. author reply e565-566.

37. Lamy PJ, Verjat T, Servanton AC, Paye M, Leissner P, Mougin B: Urokinasetype plasminogen activator and plasminogen activator inhibitor type-1 mRNA assessment in breast cancer by means of NASBA: correlation with protein expression. Am J Clin Pathol 2007, 128(3):404-413.

38. Elston CW, Ellis IO: Pathological prognostic factors in breast cancer. I. The value of histological grade in breast cancer: experience from a large study with long-term follow-up. Histopathology 1991, 19(5):403-410.

39. Mallett S, Timmer A, Sauerbrei W, Altman DG: Reporting of prognostic studies of tumour markers: a review of published articles in relation to REMARK guidelines. Br J Cancer 2010, 102(1):173-180.

40. Esteller M, Silva JM, Dominguez G, Bonilla F, Matias-Guiu X, Lerma E, Bussaglia E, Prat J, Harkes IC, Repasky EA, et al: Promoter hypermethylation and BRCA1 inactivation in sporadic breast and ovarian tumors. J Nat/ Cancer Inst 2000, 92(7):564-569.

41. Ozretic L, Rhiem K, Huss S, Wappenschmidt B, Markiefka B, Sinn P, Schmutzler RK, Buettner R: High nuclear poly(adenosine diphosphateribose) polymerase expression is predictive for BRCA1- and BRCA2deficient breast cancer. J Clin Oncol 2011, 29(34):4586-4588. 
42. Jalava P, Kuopio T, Juntti-Patinen L, Kotkansalo T, Kronqvist P, Collan Y: Ki67 immunohistochemistry: a valuable marker in prognostication but with a risk of misclassification: proliferation subgroups formed based on Ki67 immunoreactivity and standardized mitotic index. Histopathology 2006, 48(6):674-682.

43. Wei M, Xu J, Dignam J, Nanda R, Sveen L, Fackenthal J, Grushko TA, Olopade Ol: Estrogen receptor alpha, BRCA1, and FANCF promoter methylation occur in distinct subsets of sporadic breast cancers. Breast Cancer Res Treat 2008, 111(1):113-120.

44. Krasteva ME, Bozhanov SS, Antov GG, Gospodinova ZI, Angelov SG: Breast cancer patients with hypermethylation in the promoter of BRCA1 gene exhibit favorable clinical status. Neoplasma 2012, 59(1):85-91.

45. Goldhirsch A, Glick JH, Gelber RD, Coates AS, Thurlimann B, Senn HJ, Panel M: Meeting highlights: international expert consensus on the primary therapy of early breast cancer 2005. Ann Oncol 2005, 16(10):1569-1583.

46. O'Shaughnessy JS, Schwartzberg L, Danso MA, Rugo HS, Miller K, Yardley DA, Carlson RW, Finn RS, Charpentier E, Freese M: A Randomized Phase III Study of Iniparib (BSI-201) in Combination with Gemcitabine/Carboplatin (G/C) in Metastatic Triple-Negative Breast Cancer (TNBC). In American Society of Clinical Oncology: June 3-7, 2011. Chicago, Illinois: J Clin Oncol; 2011. 2011: Abstract 1007.

47. Hellebrand H, Sutter C, Honisch E, Gross E, Wappenschmidt B, Schem C, Deissler H, Ditsch N, Gress V, Kiechle M, et al: Germline mutations in the PALB2 gene are population specific and occur with low frequencies in familial breast cancer. Hum Mutat 2011, 32(6):E2176-2188.

48. Poumpouridou N, Kroupis C: Hereditary breast cancer: beyond BRCA genetic analysis; PALB2 emerges. Clin Chem Lab Med 2012, 50(3):423-434

49. Buisson R, Dion-Cote AM, Coulombe Y, Launay H, Cai H, Stasiak AZ, Stasiak A, Xia B, Masson JY: Cooperation of breast cancer proteins PALB2 and piccolo BRCA2 in stimulating homologous recombination. Nat Struct Mol Biol 2010, 17(10):1247-1254.

doi:10.1186/1471-2407-13-523

Cite this article as: Jacot et al:: BRCA1 promoter hypermethylation, 53BP1 protein expression and PARP-1 activity as biomarkers of DNA repair deficit in breast cancer. BMC Cancer 2013 13:523.

\section{Submit your next manuscript to BioMed Central and take full advantage of:}

- Convenient online submission

- Thorough peer review

- No space constraints or color figure charges

- Immediate publication on acceptance

- Inclusion in PubMed, CAS, Scopus and Google Scholar

- Research which is freely available for redistribution 